\title{
Há corpo por vir: um manifesto à presença do corpo pedagógico nas periferias
}

\author{
There will be body: a manifest for the presence of the pedagogical \\ body in the peripheries
}

\section{Hay cuerpo por venir: un manifiesto para la presencia del cuerpo pedagógico en las periferias}

\author{
Jean da Silva Menezes' \\ https://orcid.org/0000-0002-8034-8757 \\ Sidney Carlos Rocha da Silva ${ }^{2}$ \\ https://orcid.org/0000-0003-0723-955I \\ Gelson Antônio Lopes Junior ${ }^{3}$ \\ https://orcid.org/0000-0002-5 |29-740I
}

\begin{abstract}
Resumo: A presente reflexão toma a fase pandêmica junto ao pensamento contemporâneo como ponto de partida para a tematização de alguns dos dilemas que atravessam as práticas articuladoras da educação atualmente. Para isso, evocamos o discurso da desigualdade social descrita por pesquisadores de diversas áreas. No intuito de contrastar a precariedade do corpo, veremos que esse processo, já em marcha, vale-se da pandemia como pretexto ideal para a emergência das tecnologias digitais na infraestrutura pedagógica, tendo como entrave à presença viva dos alunos e professores. Nesse cenário, a esfera pedagógica encontra-se dividida entre a sempre possível resistência e a inevitabilidade da precarização do corpo. Mas, há corpo por vir!
\end{abstract}

Palavras-chave: Pandemia. Corpo. Educação.

Abstract: The present reflection takes the pandemic phase together with the contemporary thought as a starting point for the thematic usage of some of the dilemmas that cross the articulating practice of education so commonly used today. For this purpose we evoque the discourse of social inequality described by researchers from different fields of study. With the intent of contrasting the precariousness of the body we will see that this

'Mestrando em Educação pela Universidade Federal de Pernambuco (UFPE). Professor de Educação Física do Ensino Fundamental II da Prefeitura Municipal de Jaboatão dos Guararapes/PE, e professor voluntário do Núcleo Educacional Irmãos Menores de Francisco de Assis (NEIMFA). E-mail: jsmenezes2@hotmail.com

${ }^{2}$ Doutor em Educação pela Universidade Federal de Pernambuco (UFPE). Coordenador e Professor do Núcleo Educacional Irmãos Menores de Francisco de Assis (NEIMFA). E-mail: mahasidol6@yahoo.com.br

${ }^{3}$ Doutor em Educação pela Universidade Federal de Pernambuco (UFPE). Professor voluntário do Núcleo Educacional Irmãos Menores de Francisco de Assis (NEIMFA). E-mail: zenboyl84@hotmail.com

Olhar de professor, Ponta Grossa, v. 24, p. I-8, e-16206.056, 2021.

Disponível em <https://revistas2.uepg.br/index.php/olhardeprofessor> 
process, already under way, uses the pandemic as the ideal excuse for the emergence of digital technologies in the pedagogical infrastructure with the living presence of students and teachers taken as an obstacle. In this scenario, the pedagogical circle divides itself between the always possible resistance and the inevitability of the precariousness of the body. But there will be body!

Keywords: Pandemic. Body. Education.

Resumen: La presente reflexión toma la fase pandémica junto con el pensamiento contemporáneo como punto de partida para la tematización de algunos de los dilemas que atraviesan las prácticas articuladoras de la educación actual. Para esto, evocamos el discurso de la desigualdad social descrito por investigadores de diferentes áreas. Para contrastar la precariedad del cuerpo, veremos que este proceso ya en marcha, hace uso de la pandemia como pretexto ideal para el surgimiento de tecnologías digitales en la infraestructura pedagógica, teniendo como obstáculo con la presencia viva de estudiantes y docentes. En este escenário, la esfera pedagógica se divide entre la resistencia siempre posible y la inevitabilidad de la precariedad del cuerpo. Pero, hay cuerpo por venir!

Palabras-clave: Pandemia. Cuerpo. Educación.

\section{Introdução}

Este texto ecoa as inquietações recentes em torno do isolamento social, decorrentes de um vírus letal, o novo coronavírus, causador da doença Covid-19. A sua origem, principalmente no sentido de um primeiro enfrentamento coletivo e assíduo, deu-se na região de Wuhan, na China, e lançou diversos países a estados alarmantes.

Nesse sentido, filósofos como Byung-Chul Han e Giorgio Agamben lançaram dúvidas sobre o caráter emergencial da pandemia, assinalando restrições à soberania europeia submetidas à biopolítica e à psicopolítica (HAN, 2020) em um diagnóstico temeroso de um estado de exceção normalizado (AGAMBEN, 2020). Em meio à pandemia, Judith Butler é uma das filósofas que nos alerta sobre a precariedade do Estado, apontando não apenas uma desigualdade radical, mas, sobretudo, a força da solidariedade (BUTLER, 2020). São processos de aprendizagens que para a socióloga Maria da Glória Gohn se constituem em uma esperança em uma arma de combate para ir resolvendo o dia a dia (GOHN, 2020). “Uma rede solidária apoiada por corações amigos é o que nos resta” (SILVA, 2020, p. 183) para enfrentar não apenas a pandemia, mas qualquer problema, inclusive o pedagógico, "o corpo pedagógico como território de passagem". Assim, pretendemos nos manifestar dizendo: em meio ao caos, há corpo por vir!

\section{O corpo é passado, o futuro é digital}

Em resposta a esta situação paralisante, o filósofo sul-coreano Byung-Chul Han assinala que o coronavírus põe à prova nossos sistemas de defesa, destacando o aparente controle bem-sucedido de alguns países asiáticos em relação aos países europeus. Eles não se serviram meramente dos "virologistas e epidemiologistas" (HAN, 2020, p. 99), mas sobretudo dos especialistas em informática e macrodados. E adoça: que os apologistas da vigilância digital proclamariam que o big data salva vidas 
humanas (HAN, 2020).

A soberania é reavaliada! Quem a detém não fecha fronteiras, na verdade abre todas elas, principalmente as digitais. Han assinala que a soberania europeia se encontra restrita à biopolítica e à psicopolítica, motivo de seu arcaísmo soberano e ponto sensível de seu comportamento inútil e desesperado. Os europeus ficaram para trás; a nova soberania é digital.

Nosso horizonte pós-pandêmico segue o diagnóstico temeroso de Giorgio Agamben: um estado de exceção como paradigma normal de governo (AGAMBEN, 2020). Ao lado de Giorgio Agamben, Han indexa que o risco da vigilância digital pode ser maior do que o vírus, que nenhuma revolução virá dele, mas das pessoas dotadas de razão solidária (HAN, 2020). Essa é a aposta! Ambos se erguem contra o estado de pânico gerado, para acentuar o que advém por dentro dele.

Réquiem para estudantes (AGAMBEN, 2020) é um manifesto, uma chamada para ação contra o aprisionamento da experiência dos sentidos no cárcere espectral dos bárbaros da tecnologia. $A$ associação dos estudantes - que tem nos encontros, na dimensão social do fenômeno, o fundamento e a origem das universidades, por quase dois séculos - chegou ao seu fim. A parte mais vital da comunidade à associação de estudantes foi esvaziada.

A forma de vida dos estudantes, empobrecida pela ignorância das universidades, há muito já presente, agora é alvo da ditadura da realização online das aulas. É pura insanidade e aprisionamento a uma lógica meramente econômica, adesão à insanidade genocida que nos des/governa. Agamben (2020) compara essa ditadura e sua aceitação, sem protestos, ao regime fascista de 1931, no qual muitos juraram fidelidade, enquanto poucos a recusaram. Assim, ele aguarda com esse manifesto uma centelha de professores e, principalmente, de alunos que recusem inscreverem-se nesse modelo de universidade para retornarem as suas origens, fundando as novas universitates.

Pensadores solidários nacionais e internacionais lançaram-se em defesa da vida humana frente à alarmante apatia do dispositivo econômico. Diversos filósofos, sociólogos, psicólogos, pedagogos e demais pesquisadores se incumbiram em dar visibilidade ao que foi descoberto através da pandemia, descrevendo o que já estava em curso, mas constantemente velado, e alertando sobre o horizonte que nos espreita.

Curiosamente, professores e alunos esperançam a inclusão digital total. Nesse horizonte, na fronteira do indeterminado e do impensável, medidas são tomadas a partir do desdobramento de vários argumentos que favoreçam a sensação de ordem, assegurando algum retorno à normalidade. É nessa fronteira que instituições de ensino, sobremaneira na esfera privada, ansiosamente atendem às reivindicações das famílias no acompanhamento dos estudos de seus filhos, com o intuito de amenizar os impactos do ano letivo, garantindo que os conteúdos básicos sejam transmitidos.

A maior parte do debate, devido à desigualdade social, parece residir em torno da necessária

Olhar de professor, Ponta Grossa, v. 24, p. I-8, e-16206.056, 2021.

Disponível em <https://revistas2.uepg.br/index.php/olhardeprofessor> 
inclusão. Por isso, a socióloga Maria da Glória Gohn, partindo de preocupações pedagógicas, destaca as aprendizagens do mundo da vida descortinadas pela pandemia, como a emergência das novas tecnologias que intensificaram a desigualdade social.

O uso das tecnologias de comunicação, que alavancaram novas formas de relacionamento (como a construção de narrativas próprias), nas mãos dos agentes econômicos, acirrou a precariedade social. A concentração digital da relação social é um de seus sintomas, razão pela qual indivíduos, sobremaneira, pobres, moradores de rua, usuários de drogas nas cracolândias, sem celulares, sem aplicativos, não tinham como se inscrever nos programas emergenciais do governo de ajuda financeira (GOHN, 2020). A solidariedade passa então "a ser uma esperança e uma arma de combate para ir resolvendo o dia a dia" (GOHN, 2020, p. 16).

\section{Estado precário e corpo pedagógico}

Solidariedade é palavra de ordem. Judith Butler é uma das filósofas que nos alerta sobre a precariedade já em andamento, dilatada na pandemia, e que nos força a reconhecer nossa interdependência global durante o novo tempo e espaço imposto pela situação pandêmica (BUTLER, 2020). Para ela, parece provável que teremos pela frente um cenário no qual algumas criaturas humanas afirmarão seu direito de viver ao custo de outras vidas (BUTLER, 2020). Mas há um preço alto pela negação que é o retorno na forma de sintomas, violências e todas as mazelas sociais.

Deveríamos pensar estratégias de apoio para esta catástrofe. Pensar em retorno sem equanimidade é apoiar a política de exclusão do atual governo, também presente ao longo da história da educação brasileira.

Na saúde, a situação criada pela pandemia da Covid-19 vem demonstrar essa política neoliberal falida em sua tese individualista de um "capital de saúde"4, inserida na ideia de mundo social individual, que todos precisam preservá-lo, valorizá-lo ou melhorá-lo. Uma situação que tem sido desmentida nos últimos meses em escala planetária.

A precarização destacada escancara uma desigualdade radical (BUTLER, 2020) decorrente de políticas nacionalistas e fronteiriças, unidas em muitos casos ao "racismo, à xenofobia e ao capitalismo" (BUTLER, 2020, p. 62). Desigualdade acompanhada ainda por supremacia branca, violência contra pessoas LGBTQI+, mulheres e crianças. Por isso, aposta-se na possibilidade de inventarmos um mundo atravessado por um desejo coletivo radicalmente voltado à igualdade, um mundo em que possamos

\footnotetext{
${ }^{4}$ Este postulado, parte integrante de uma concepção individualista do mundo social (cuja máxima poderia ser: a sociedade é apenas uma soma de indivíduos), está mais amplamente no cerne de todas as políticas neoliberais, como, por exemplo, no cerne do desmantelamento em curso dos sistemas de pensões que consiste, precisamente, na instituição de uma "conta de pontos individuais". Quanto à noção de capital de saúde, ela é apenas uma variação da noção mais geral de "capital humano" desenvolvida por Gary Becker (BUTLER, 2020).
}

Olhar de professor, Ponta Grossa, v. 24, p. I-8, e-16206.056, 202 I.

Disponível em <https://revistas2.uepg.br/index.php/olhardeprofessor> 
Jean da Silva Menezes, Sidney Carlos Rocha da Silva e Gelson Antônio Lopes Junior nos unir no sentido de uma saúde pública e universal (BUTLER, 2020).

É preciso concordar com Butler (2020) e Gohn (2020), que a pandemia descortinou a desigualdade social. Mas, para quem agora se alarma, alerta Silva (2020), a pandemia nos trouxe de volta à existência real. A precariedade pode ter sido amplamente descortinada, mas ela já estava aí. Agora é a possibilidade de aprendermos a cuidar do próximo, que também já estava aí. $O$ que a pandemia abriu não foi a possibilidade de aprendermos com o mundo da vida, mas sim com ○ já presente deserto do viral, intensificando o já em andamento modo favela do cuidado de uns com os outros (SILVA, 2020).

Mais do que nunca presenciamos nosso acentuado fracasso. "A Europa está fracassando" (HAN, 2020, p. 98), muito diferente do sucesso chinês. Leitos, respiradores e máscaras se mostram ausentes decorrentes da política de austeridade e dos desinvestimentos na preparação médica de emergência. A reação emergencial é escassa e escancara a divisão social do sistema de saúde público e privado.

Além disso, falta uma renda do assalariado para lidar com uma emergência desse nível, o qual se vê obrigado "a enfrentar a desagradável escolha da contaminação em nome do cuidado e da manutenção de elementos-chave de provisão (como supermercados) abertos ou do desemprego sem benefício" (HARVEY, 2020, p. 2I). E por que não dizer dos professores demitidos ou com seus contratos suspensos em plena pandemia. Desamparo!

A pandemia agravou situações sociais, uma crise de classes, divididas entre aqueles que enfrentam dificuldades de vivência e sobrevivência. Mas, em outro cenário, para além da querela social, o mundo parece agradecer. Rios se recuperam, animais reaparecem e o ar torna-se mais respirável. Isso assinala que a Covid-19 não é "só" uma questão de saúde pública; é também um problema de natureza social, governamental, ética, ecológica. É, acima de tudo, um problema de política cósmica (SILVA, 2020).

Presenciamos a irrupção sucessiva de doenças no sistema imunológico inexperiente da humanidade. $O$ fato da sucessão já nos diz da familiaridade que temos com o vírus, um "monstro familiar" (DAVIS, 2020, p. 6). Ele não pulou o muro de nossas casas à noite. Ele entrou durante o dia pela porta da frente, expondo o quanto estamos despreparados. Estamos à mercê!

O que nos resta? Enfrentar esse problema como sempre fizemos: procurando nos apoiar, nos ajudar, nos fortalecer, vendo quem precisa do que, trazendo informações mais contextualizadas e de forma cuidadosa; enfim, articulando forças, movimentos, pessoas e, sobretudo, corações por meio de uma rede amiga e solidária (SILVA, 2020).

Não apostamos no Estado, embora saibamos de suas responsabilidades sociais e políticas. Aqui, entendemos que uma rede solidária apoiada por corações amigos é o que nos resta para enfrentar não

Olhar de professor, Ponta Grossa, v. 24, p. I-8, e-16206.056, 2021.

Disponível em <https://revistas2.uepg.br/index.php/olhardeprofessor> 
Há corpo por vir: um manifesto à presença do corpo pedagógico nas periferias

apenas a pandemia, mas qualquer problema. É preciso cobrar o direito à vida, denunciando que ela não é privilégio de uma parcela da população e que as periferias não são territórios para matar e morrer, mas lugar onde se potencializa a vida através do cuidado uns com os outros (SILVA, 2020). Lugar que nos oferece uma resposta do coletivo, e não uma sobrecarga do individual. Há corpo nas favelas. "Como território de passagem, é por meio dele que se movimentam os processos de aprendizagens" (SILVA, 2020, p. 183).

Por isso, a auto-organização, as políticas da amizade ou as redes de solidariedade são diferenças enquanto pensamentos estratégicos característicos das favelas. NEIMFA, AVIPA, MABI, Rede Coque Rexiste e Coletivo Caranguejo Tabaiares Resiste são alguns movimentos sociais que ecoam afetos solidários, que não cruzam os braços, não caducam alternativas ou se ausentam enquanto povo ameaçado. Nesse caso, pensar diferentemente é a capacidade de transformar-se constantemente.

A periferia tem mostrado que a política nunca será privilégio dos políticos. Ela ecoa gritos do que costumeiramente é emudecido a partir de mídias alternativas e contra hegemônicas como as "anuncicletas", as campanhas de doações, a confecção de máscaras e o atendimento psicossocial. Esses são alguns exercícios solidários praticados nas periferias para o enfrentamento de situações adversas a partir do corpo tomado - ou tombado - como território de afecção e não como organismo (SILVA, 2020).

O modo favela abre um tempo comunitário e dadivoso, alertando a insuficiência do lucro, e de ações pontuais como "meu grupo", "meus bens", "minha parte". Dispõe o tempo de aprender um destino comum, um fazer que se sustenta coletivamente, ecoando uma luta contra a lógica que insiste em focar no equilíbrio fiscal em detrimento do compromisso social (SILVA, 2020). Buscamos destacar que a presença da pandemia não apenas nos trouxe de volta à existência real ou mesmo que as tecnologias digitais escancararam em massa a desigualdade social. $O$ que nos preocupa pedagogicamente com a tecnologia digital não é o diagnóstico de uma necessária inclusão (uma desprecarização digital), mas a exclusão dos corpos de professores e alunos. Há corpo por vir!

\section{Considerações finais}

Não temos dúvidas da importância e urgência do retorno das aulas. Como vimos com Butler (2020), o confinamento colide com "uma desigualdade social radical” (BUTLER, 2020, p. 6I). Por isso, a solidariedade advém como esperança e meio hábil de combate para ir desintrincando nosso cotidiano (GOHN, 2020).

Assim, não podemos esperar, com um mínimo de sanidade, que as questões implicadas por um viés meramente digital possam resolver as questões de natureza pedagógica justamente em meio a uma pandemia. É preciso reimaginar nosso mundo (BUTLER, 2020). É urgente potencializar a vida 
Jean da Silva Menezes, Sidney Carlos Rocha da Silva e Gelson Antônio Lopes Junior

procurando promover o cuidado de uns com os outros, o vírus somos nós (HAN, 2020).

Mas, esse "nós" deve ser compreendido enquanto capacidade de afetar e ser afetado pelos fluxos energéticos que vêm de outros corpos no encontro com o nosso (SILVA, 2020). Não podemos fantasiar que o debate sobre atividades remotas de ensino esteja circunscrito à posse ou não de condições instrumentais mínimas, uma vez que o potencial de aprendizagem de uma subjetividade está no corpo, não fora dele (SILVA, 2020).

Nessa perspectiva, compreende-se que o professor não corresponde concretamente apenas em transmitir conhecimentos. Os afetos são indispensáveis na relação pedagógica. Numa aula presencial, professores compreendem humores, afetando e sendo afetado, concebem impasses, percebem dificuldades e têm como princípio a manifestação da consistência ético-epistêmica no exercício da docência, junto aos seus pares, dentro e fora do centro de ensino.

Como pesquisadores empenhados em pensar e pesquisar a partir do ponto de vista éticopolítico-existencial, insistimos na apreensão da formação humana em aspecto multidimensional, compreendendo que a Covid-19 não é "só" uma questão de saúde pública; é também um problema de natureza social, governamental, ética, ecológica. É, acima de tudo, um problema de política cósmica (SILVA, 2020).

Em meio ao estado precário e digital, coemerge das periferias auto-organizações enquanto políticas da amizade e redes de solidariedade que movimentam processos de aprendizagens (GOHN, 2020; SILVA, 2020) vinculadas à presença e ao cuidado. São corpos tomados - ou tombados - como territórios de afecções, e não como organismos, que nos convocam a uma experiência nova não só do falar, do decantar, do parar, mas também do abraçar, do compartilhar, do ensinar, do aprender (SILVA, 2020). Afinal, o corpo pedagógico já está aí!

\section{Referências}

AGAMBEN, G. Réquiem para os estudantes. São Paulo: $\mathrm{N}$-I edições, 2020. Disponível em: https://n-l edicoes.org/. Acesso em: 10 jun. 2020.

BADIOU, A. Sobre a situação epidêmica. In. DAVIS, Mike et. al. Coronavírus e a luta de classes. Terra sem Amos: Brasil, 2020. p. 35-42.

BIHR, A. França: pela socialização do aparato de saúde. In. DAVIS, Mike et. al. Coronavírus e a luta de classes. Terra sem Amos: Brasil, 2020. p. 25-30.

BUTLER, Judith. El capitalismo tiene sus límites. In. AGAMBEN, Giorgio et. al. Sopa de Wuhan: pensamiento contemporáneo en tiempos de pandemias. I ${ }^{a}$ ed. Aspo [SI]: março, 2020. p. 5965 .

DAVIS, M. A crise do coronavírus é um monstro alimentado pelo capitalismo. In. DAVIS, Mike et. al. Coronavírus e a luta de classes. Terra sem Amos: Brasil, 2020. p. 5-I2. 
GOHN, M. da G. Educação não formal: direitos e aprendizagens dos cidadãos (ãs) em tempos de coronavírus. Revista Humanidades e Inovação: Educação formal e não formal, cultura e currículo II. Palmas, v. 7, n. 7, mar. 2020.

HAN, B. C. La emergencia viral y el mundo de mañana. In. AGAMBEN, Giorgio et. al. Sopa de Wuhan: pensamiento contemporáneo en tiempos de pandemias. I $^{\mathrm{a}}$ ed. Aspo [SI]: março, 2020. p. 97-III.

HARVEY, D. Política anticapitalista em tempos de COVID-19. In. DAVIS, Mike et. al. Coronavírus e a luta de classes. Terra sem Amos: Brasil, 2020. p. I3-23.

LATOUR, B. Imaginar gestos que barrem o retorno da produção pré-crise. São Paulo: N-I edições, 2020. Disponível em: https://n- ledicoes.org/. Acesso em: 10 jun. 2020.

SAFATLE, V. Bem-vindo ao estado suicidário. São Paulo: N-I edições, 2020. Disponível em: <https://n-ledicoes.org/>. Acesso em: 10 jun. 2020.

SILVA, S. R. Educação e espiritualidade em Chögyam Trungpa Rinpoche: nos rastros de uma pedagogia fantástica. 2020. Tese (Doutorado em Educação) - Universidade Federal de Pernambuco, Recife, 2020.

SILVA, S. R. Favela, covid 19 e a potência dos pobres: resistindo entre a política da amizade e os laços de solidariedade. 2020. Disponível em: http://marcozero.org/favela-covid- I9-e-a-potenciados-pobres-resistindo-entre-a-politica-da-amizade-e-os-laços-de-solidariedade/. Acesso em: 10 jun. 2020.

ZIZEK, S. Um golpe como "Kill Bill” no capitalismo. In. DAVIS, Mike et. al. Coronavírus e a luta de classes. Terra sem Amos: Brasil, 2020. p. 43-47.

Recebido em: 18 de junho de 2020.

Versão corrigida recebida em: 0I de dezembro de 2020.

Aceito em: 0I de dezembro de 2020.

Publicado online em: 04 de junho de 202I.

Olhar de professor, Ponta Grossa, v. 24, p. I-8, e-I6206.056, 202I.

Disponível em <https://revistas2.uepg.br/index.php/olhardeprofessor> 